\title{
Suitability of various materials for porous filters in diffusion experiments
}

\begin{abstract}
The suitability of different porous materials (stainless steel, VYCOR ${ }^{\circledR}$ glass, $\mathrm{Al}_{2} \mathrm{O}_{3}$ and PEEK) for use as confining filters in diffusion experiments was evaluated by measuring the effective diffusion coefficients $\left(D_{\mathrm{e}}\right)$ of neutral (HTO) and ionic solutes $\left(\mathrm{Na}^{+}, \mathrm{Cs}^{+}, \mathrm{Sr}^{2+}, \mathrm{Cl}^{-}\right.$, $\mathrm{SeO}_{4}{ }^{2-}$ ) in the materials in through-diffusion experiments. For stainless steel filters, the $D_{\mathrm{e}}$ values of the target solutes correlated satisfactorily with their bulk diffusion coefficient in water $\left(D_{\mathrm{w}}\right)$; thus, the diffusion process in the stainless steel filters was primarily controlled by the diffusivity of the solvated ions. For the remaining materials, the $D_{\mathrm{e}}$ and $D_{\mathrm{w}}$ values were also correlated for the target solutes, and the geometric factors were in the sequence: VYCOR ${ }^{\circledR}$ glass $<\mathrm{Al}_{2} \mathrm{O}_{3}<$ PEEK. Stainless steel and VYCOR ${ }^{\circledR}$ glass were the most appropriate materials because of their high $D_{\mathrm{e}}$ values, but a specific interaction of caesium with VYCOR ${ }^{\circledR}$ glass was hypothesised because the $D_{\mathrm{e}}$ values obtained for this solute were slightly higher than expected.
\end{abstract}

Keywords: Effective diffusion coefficient, porous filter, Archie's relationship, geometric factor.

\footnotetext{
*Corresponding Author: Anna Rigol, Departament de Química Analítica, Universitat de Barcelona, 08028-Barcelona, Spain, e-mail: annarigol@ub.edu

David Aldaba, Miquel Vidal: Departament de Química Analítica, Universitat de Barcelona, 08028-Barcelona, Spain

Martin Glaus, Luc Van Loon: Laboratory for Waste Management, Paul Scherrer Institut, 5232 Villigen PSI, Switzerland Olivier Leupin: Nagra, 5430 Wettingen, Switzerland
}

\section{Introduction}

Based on international consensus [1] for the disposal of high-level radioactive waste (HLW) and spent fuel (SF), geological repositories have been promoted as the safest option to isolate the waste from the biosphere. In most versions of these repositories, the isolation of waste from the biosphere relies on passive multi-barrier systems. The space around the emplaced canisters is usually back- filled with swelling clay to reduce the hydraulic conductivity in the near field to values similar to those measured in the host rock [2, 3] and to ensure diffusioncontrolled transport of radionuclides when the canisters are breached [4]. Thus, the development and application of laboratory methodologies for the characterisation of the diffusion of the radionuclides present in spent nuclear fuel and high-level waste in the compacted materials used in engineered barriers has become an important issue for long-term safety considerations.

The diffusive transport of radionuclides through a porous medium is quantified by the effective diffusion coefficient $\left(D_{\mathrm{e}}\right)$, which includes the effect of the geometric properties of the pores of the material on the diffusion of the target solutes. Therefore, $D_{\mathrm{e}}$ depends, among other terms, on the porosity accessible for diffusion, the pore diameter and the connectivity of the porous network [5]. In this sense, the diffusion of various radionuclides through compacted swelling clays and argillaceous rocks has been extensively evaluated in laboratory tests by obtaining the $D_{\mathrm{e}}$, primarily by through-diffusion experiments. The literature on through-diffusion experiments is vast but important references are: Molera and Eriksen [6], in which the diffusion of ${ }^{22} \mathrm{Na}^{+},{ }^{85} \mathrm{Sr}^{2+},{ }^{134} \mathrm{Cs}^{+}$and ${ }^{57} \mathrm{Co}^{2+}$ in compacted bentonite was studied as a function of different compaction densities; Van Loon et al. [7], who applied through-diffusion and the complementary out-diffusion method to study the diffusion of $\mathrm{HTO},{ }^{36} \mathrm{Cl}^{-}$and ${ }^{125} \mathrm{I}^{-}$in Opalinus Clay under different confining pressures; and Glaus et al. [8], who investigated the diffusion of HTO, ${ }^{22} \mathrm{Na}^{+}$and ${ }^{36} \mathrm{Cl}^{-}$in compacted kaolinite, illite and montmorillonite as a function of the concentration of background electrolyte in the solution in contact with the clay sample.

The through-diffusion method usually requires a sandwiched filter-clay-filter experimental setup. The filters allow the tracer solution to enter and leave the clay samples [9] and maintain sample integrity. Moreover, in experiments with swelling clays (mainly compacted bentonites), stainless steel filters are often preferred because they can resist the high swelling pressures $[6,9]$. The effect of the filters on the diffusion process is usually neglected; the prevailing argument for this neglect is that 
the solute diffusivity is much higher in filters than in clays. However, only a few studies have systematically evaluated radionuclide diffusion in stainless steel porous filters as a preliminary step [6,9]. Thus, Molera and Eriksen [6] measured the diffusivities of solutes through stainless steel porous filters, and included these diffusivities in a model for solute diffusion in compacted bentonite. Glaus et al. [9] measured the $D_{\mathrm{e}}$ values of various solutes in stainless steel porous filter discs before and after the use of these discs in diffusion experiments with clay minerals, and they concluded that used filters might impede solute diffusion because of the clogging of filter pores by clay. However, other factors, such as pore geometry or possible solute-filter interactions in unused filters, might also affect the $D_{\mathrm{e}}$ values obtained in through-diffusion experiments and have not yet been evaluated. This evaluation could be performed by examining the diffusivities of a series of uncharged, positively and negatively charged solutes in a set of presumably inert porous media; this approach has not yet been fully and systematically tested in the literature.

Thus, in this work, the effect of the pore geometry (porosity, pore diameter and connectivity) on the quantification of $D_{\mathrm{e}}$ by through diffusion [9], as well as the potential existence of solute-filter interactions, was evaluated in various materials for a series of solutes (HTO, $\mathrm{Na}^{+}, \mathrm{Cs}^{+}, \mathrm{Sr}^{2+}, \mathrm{Cl}^{-}, \mathrm{SeO}_{4}^{2-}$ ), either radionuclides or, for safety, stable elements representative of relevant radionuclides. Archie's relationship [10] was assessed for stainless steel porous filters with different pore diameters and porosities. In addition, the applicability of other materials (VYCOR ${ }^{\circledR}$ glass, $\mathrm{Al}_{2} \mathrm{O}_{3}$ and PEEK) for use as filters in through-diffusion experiments was also evaluated based on the relationship between the $D_{\mathrm{e}}$ values obtained for the target solutes in these materials and the corresponding diffusion coefficients of the solutes in free water $\left(D_{\mathrm{w}}\right)$.

\section{Experimental}

\subsection{Materials and reagents}

The stainless steel filters used in this study were purchased from MOTT industrial division (Code 316L, Farmington, Connecticut, USA). The pore diameters of the filters were 10, 5, 2, 1 and $0.5 \mu \mathrm{m}$. The diameter of the discs was $25.4 \mathrm{~mm}$, and the thickness was $1.5 \mathrm{~mm}$. VYCOR ${ }^{\circledR}$ glass filter discs, composed of $96 \% \mathrm{SiO}_{2}, 3 \% \mathrm{~B}_{2} \mathrm{O}_{3}$ and $0.4 \% \mathrm{Na}_{2} \mathrm{O}$, were provided by Corning Incorporated (New York, USA). Typical pore sizes are of the order of $4 \mathrm{~nm}$. Filters made from porous $\mathrm{Al}_{2} \mathrm{O}_{3}$ were provided by Metoxit
(Thayingen, Switzerland). Only the particle size for the sintering process is known for this material (order of $5 \mu \mathrm{m}$ ); typical pore sizes are thus in the low $\mu \mathrm{m}$ range. The PEEK (Polyether ether ketone) filters were provided by Porogen (Woburn, MA, USA). The diameter of the disks was $25.6 \mathrm{~mm}$ in all cases and typical pore sizes for this material are in the $1 \mu \mathrm{m}$ range. The thickness of the filter discs ranged from 1.00 to $1.03 \mathrm{~mm}$ for VYCOR ${ }^{\circledR}$ glass, from 1.50 to $1.53 \mathrm{~mm}$ for $\mathrm{Al}_{2} \mathrm{O}_{3}$, and from 1.65 to $1.68 \mathrm{~mm}$ for PEEK.

The porosities $(\varepsilon)$ of all the filters tested were calculated from the weights of the dry and water-saturated filters.

P.A. grade $\mathrm{CsCl}, \mathrm{SrCl}_{2}$ and $\mathrm{KCl}$ were purchased from Fluka (Buchs, Switzerland). Radioisotopically pure solutions of $\mathrm{HTO},{ }^{22} \mathrm{Na}^{+},{ }^{36} \mathrm{Cl}^{-},{ }^{134} \mathrm{Cs}^{+}$and ${ }^{75} \mathrm{SeO}_{3}{ }^{2-}$ were obtained from Isotope Products Europe (Blaseg, Germany). Selenite was oxidised to selenate with $\mathrm{NaClO}$ based on similar procedures described in Glaus et al. [11] for the oxidation of iodide to iodate. The subsequent isolation of the reaction product by semi-preparative high-performance anion chromatography was performed with an IonPac AS18 column (Dionex, Switzerland).

\subsection{Through-diffusion experiments}

For the through-diffusion experiments, the manufactured acrylic diffusion cells developed in a previous work [9] were used. Figure 1 shows a schematic of this experimental setup, which is composed of two solution reservoirs of $125 \mathrm{~mL}$ separated by the filter. Advective solute transport was prevented by the use of FKM fluoroelastomer flat seals (Angst + Pfister, Switzerland) that encased the filters. Once assembled, the cells were filled with approximately $115 \mathrm{~mL}$ of electrolyte solution $\left(\mathrm{NaClO}_{4} 0.1 \mathrm{~mol} \mathrm{~L}^{-1}\right)$ and subjected to vacuum in a desiccator for approximately $15 \mathrm{~min}$ to evacuate any air trapped in the pore space of the filters. Then, the cells were allowed to stand for $24 \mathrm{~h}$ to ensure that the level of the solution was identical in both reservoirs. The solutions were stirred magnetically to maintain homogeneity. No special precaution was taken to fix the $\mathrm{pH}$ in the solutions. It can be assumed that $\mathrm{pH}$ was largely controlled by uptake of $\mathrm{CO}_{2}$.

At the beginning of the experiments, $500 \mu \mathrm{L}$ of a solution containing the target solute was added to one of the reservoirs (the source reservoir), and a similar amount of solution without the solute was simultaneously added to the other reservoir (the target reservoir). The initial concentration of solute added to the source reservoir was determined to facilitate quantification of the solute. This initial concentration was $1 \mathrm{MBqL}^{-1}$ for the radionuclides 


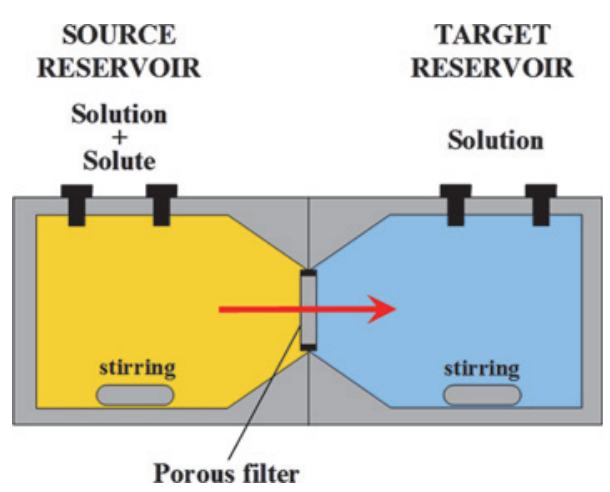

Fig. 1: Experimental setup for the through-diffusion method.

and $3 \mathrm{mmol} \mathrm{L}^{-1}$ for the stable elements. Once the diffusion process had started, $250 \mu \mathrm{L}$ aliquots were simultaneously removed from both reservoirs, and special care was used to avoid fluxes between the reservoirs that could lead to advective transport of the target solute. Aliquots were removed every $1.5 \mathrm{~h}$ for approximately $7 \mathrm{~h}$, and afterwards, additional aliquots were removed during the diffusion experiments, which lasted up to $10 \mathrm{~d}$.

Through-diffusion experiments with stainless steel filters were performed, on one hand, with a mixture of HTO and ${ }^{22} \mathrm{Na}^{+}$and, on the other hand, with a mixture of stable $\mathrm{Cl}^{-}, \mathrm{Cs}^{+}$and $\mathrm{Sr}^{2+}$, as analogues of radionuclides. For the evaluation of the remaining materials, three through-diffusion experiments were performed in parallel with a mixture of $\mathrm{HTO}$ and ${ }^{36} \mathrm{Cl}^{-}$, with ${ }^{134} \mathrm{Cs}^{+}$and with ${ }^{75} \mathrm{SeO}_{4}{ }^{2-}$.

\subsection{Measurement of solute concentrations}

\subsubsection{Experiments with stainless steel filters}

The concentrations of HTO and ${ }^{22} \mathrm{Na}^{+}$present in the sampled aliquots were simultaneously determined by liquid scintillation with a Tri-carb 2250 CA counter (CanberraPackard). The $250 \mu \mathrm{L}$ sample aliquots were mixed with $10 \mathrm{~mL}$ of deionized water and $10 \mathrm{~mL}$ of scintillation cocktail (Ultima Gold XR, Canberra-Packard) for the measurements. $\beta$ - $\beta$ discrimination was used in two energy windows: $0-9 \mathrm{keV}$ for HTO and $9-160 \mathrm{keV}$ for ${ }^{22} \mathrm{Na}^{+}$. The lower energy window covered scintillation signals caused by the two radionuclides, while the upper window was specific for ${ }^{22} \mathrm{Na}^{+}$. The activity of ${ }^{22} \mathrm{Na}^{+}$was thus determined unequivocally from the upper window, and this information was subsequently used for determining the activity of HTO.
The concentrations of stable $\mathrm{Cs}^{+}$and $\mathrm{Sr}^{2+}$ were measured by high-performance cation exchange chromatography (HPCEC) by a Dionex DX-600 system (Dionex, Switzerland) consisting of a metal-free GP50-2 quaternary gradient pump, a CD25A conductivity detector and an AS50 autosampler, equipped with a 9750 motor-driven Rheodyne injection valve and a $50 \mu \mathrm{l}$ PEEK injection loop. The separation column was a $4 \mathrm{~mm} \times 250 \mathrm{~mm}$ IonPac CS12A used in combination with a $4 \mathrm{~mm} \times 50 \mathrm{~mm}$ IonPac CG12A guard column (Dionex, Switzerland). The eluent was $18 \mathrm{mmol} \mathrm{L}^{-1}$ methanesulphonic acid at a flow rate of $1 \mathrm{~mL} \mathrm{~min}^{-1}$. For stable $\mathrm{Cl}^{-}$, a $4 \mathrm{~mm} \times 250 \mathrm{~mm}$ IonPac AS16 separation column and a $4 \mathrm{~mm} \times 50 \mathrm{~mm}$ IonPac AG16 guard column (Dionex, Switzerland) were used for the separation. The eluent was $0.02 \mathrm{~mol} \mathrm{~L}^{-1} \mathrm{NaOH}$ at a flow rate of $1 \mathrm{~mL} \mathrm{~min}{ }^{-1}$. Conductivity after electrochemical eluent suppression (autosuppression mode) was applied in both cases for analyte detection.

\subsubsection{Experiments with $\mathrm{VYCOR}^{\circledR}$ glass, $\mathrm{Al}_{2} \mathrm{O}_{3}$ and PEEK filters}

The concentration activities of HTO and ${ }^{36} \mathrm{Cl}^{-}$present in the aliquots sampled were determined simultaneously by liquid scintillation with a Tri-carb 2250 CA counter (Canberra-Packard). The $250 \mu \mathrm{L}$ sample aliquots were mixed with $10 \mathrm{~mL}$ of deionized water and $10 \mathrm{~mL}$ of scintillation cocktail (Ultima Gold XR, Canberra-Packard) for the measurements. $\beta$ - $\beta$ discrimination was used in two energy windows of 0 to $9 \mathrm{keV}$ for HTO and 9 to $710 \mathrm{keV}$ for ${ }^{36} \mathrm{Cl}^{-}$. The lower energy window covered scintillation signals caused by the two radionuclides, while the upper window was specific for ${ }^{36} \mathrm{Cl}^{-}$. The activity of ${ }^{36} \mathrm{Cl}^{-}$was thus determined unequivocally from the upper window, and this information was subsequently used for determining the activity of HTO. The concentration activities of ${ }^{134} \mathrm{Cs}^{+}$ and ${ }^{75} \mathrm{SeO}_{4}{ }^{2-}$ were determined with a $\gamma$-counter (Minaxi$\gamma$, Autogamma 5000 series, Canberra-Packard) in spectral windows of $615-675 \mathrm{keV}$, and $76-136 \mathrm{keV}$, respectively.

\subsection{Determination of the $D_{\mathrm{e}}$ values}

The breakthrough curve for the solute was obtained by plotting the accumulated activity (in $\mathrm{kBq}$, for radionuclides) or the accumulated mass (in mol, for stable elements) in the target reservoir as a function of time (s). Although the concentration changes are not linear with time because of variable boundary conditions in the source reservoir, the initial phase of the process $(1-8 \mathrm{~h})$ can be 
treated as being pseudo-linear because the concentration in the source reservoir did not change significantly during this time span. Subsequently, the curve evolved nonlinearly until the concentration of the solute was equal in both reservoirs. For example, Figure 2a shows the breakthrough curve of HTO for the experiments with $\mathrm{VYCOR}^{\circledR}$ glass filter, and Figure $2 \mathrm{~b}$ shows the linear fit of the pseudo-linear phase.

The $D_{\mathrm{e}}$ value for a given experiment was calculated by applying the following equation [9]:

$$
D_{\mathrm{e}}=\frac{a L_{\mathrm{e}}}{S C_{0}}
$$

where $a\left(\mathrm{kBq} \mathrm{s}^{-1}\right.$ or $\left.\mathrm{mol} \mathrm{s}^{-1}\right)$ is the slope of the breakthrough curve obtained from a linear regression of the pseudo-linear phase, $L_{\mathrm{e}}(\mathrm{m})$ and $S\left(\mathrm{~m}^{2}\right)$ are, respectively, the thickness and the cross-sectional area of the filter disc, and $C_{0}$ is the initial concentration $\left(\mathrm{kBq} \mathrm{m}^{-3}\right.$ or $\left.\mathrm{mol} \mathrm{m}^{-3}\right)$ in the source reservoir.

No anomalies were detected in the diffusion experiments because the initial concentration of each given so-
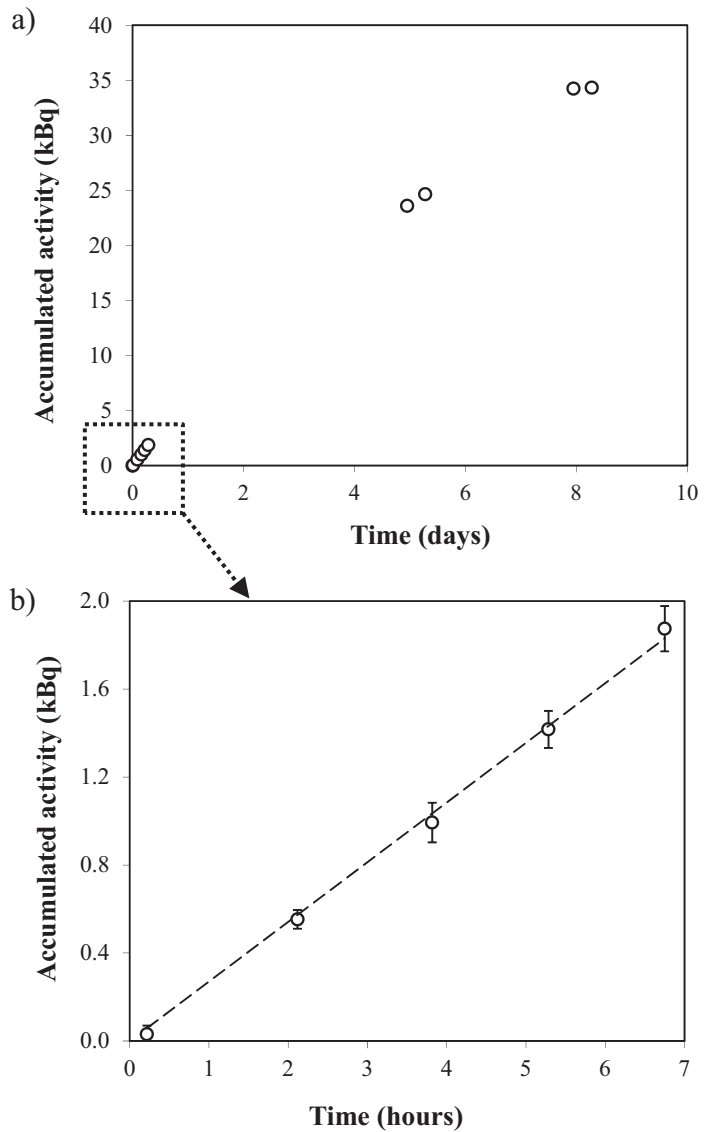

Fig. 2: (a) Breakthrough curve for HTO and (b) pseudo-linear phase of the breakthrough curve in the target reservoir for the experiments with the VYCOR ${ }^{\circledR}$ glass filter. lute matched well $( \pm 5 \%)$ the sum of the final concentrations of the solute in the source and target reservoirs at the end of the experiment.

The global errors in the $D_{\mathrm{e}}$ values were calculated by propagation of the errors associated with the parameters involved in Eq. (1). The errors were lower than $10 \%$ in all cases, and the main source of error originated from the calculation of the slope.

\section{Results and discussion}

\subsection{Effective diffusion coefficients for the stainless steel porous filters}

Table 1 summarises the effective diffusion coefficients of the target solutes for each pore diameter and porosity tested for the stainless steel porous filters.

For a given pore diameter and porosity, the results followed the sequence $D_{\mathrm{e}}(\mathrm{HTO})>D_{\mathrm{e}}\left(\mathrm{Cs}^{+}\right) \sim D_{\mathrm{e}}\left(\mathrm{Cl}^{-}\right)>$ $D_{\mathrm{e}}\left(\mathrm{Na}^{+}\right)>D_{\mathrm{e}}\left(\mathrm{Sr}^{2+}\right)$; this sequence matches the sequence of the bulk diffusion coefficients in water $\left(D_{\mathrm{w}}\right)$ reported in the literature [12-14]. As shown in Figure 3a, the $D_{\mathrm{e}}$ values obtained for all the examined solutes showed a satisfactory linear correlation $\left(0.92<R^{2}<0.98\right)$ with the respective $D_{\mathrm{w}}$ values. The linear relation between $D_{\mathrm{w}}$ and $D_{\mathrm{e}}$ values was evaluated through the well-established formalism for the diffusion of a solute in a saturated porous system [15]:

$$
D_{\mathrm{e}}=\frac{\varepsilon}{G} D_{\mathrm{w}}
$$

where $G$ is the overall geometric factor, which accounts for the geometric properties of the pore network, such as the constrictivity and tortuosity. $G$ values were calculated

Table 1: Pore diameter, porosity $(\varepsilon), D_{\mathrm{e}}$ values and geometric factor (G) obtained by through-diffusion experiments with stainless steel porous filters.

\begin{tabular}{lccccccc}
\hline \multirow{2}{*}{$\begin{array}{l}\text { Pore dia- } \\
\text { meter }(\mu \mathrm{m})\end{array}$} & $\boldsymbol{\varepsilon}^{\mathrm{a}}$ & \multicolumn{5}{c}{$\mathrm{D}_{\mathrm{e}}\left(\mathbf{1 0 ^ { - 1 0 }} \mathbf{m}^{2} \mathbf{s}^{-1}\right)^{\mathbf{b}}$} & $\mathbf{G}$ \\
\cline { 3 - 7 } & & $\mathbf{H T O}$ & $\mathbf{C s}^{+}$ & $\mathbf{C l}^{-}$ & $\mathbf{N a}^{+}$ & $\mathbf{S r}^{2+}$ & \\
\hline 10 & $0.286(0.016)$ & 2.0 & 1.7 & 1.8 & 1.3 & 0.81 & 3.4 \\
5 & $0.318(0.002)$ & 2.6 & 2.2 & 2.1 & 1.6 & 0.92 & 3.0 \\
2 & $0.295(0.001)$ & 2.6 & 2.2 & 2.2 & 1.6 & 0.93 & 2.8 \\
1 & $0.235(0.001)$ & 1.7 & 1.3 & 1.5 & 1.0 & 0.51 & 3.5 \\
0.5 & $0.190(0.001)$ & 1.1 & 0.92 & 0.97 & 0.65 & 0.39 & 4.2 \\
\hline
\end{tabular}

${ }^{a}$ Mean (standard deviation) given for measurements on 10 different filters from the same production lot.

${ }^{\mathrm{b}}$ The error associated with the $D_{\mathrm{e}}$ values was less than $10 \%$ in all cases. 

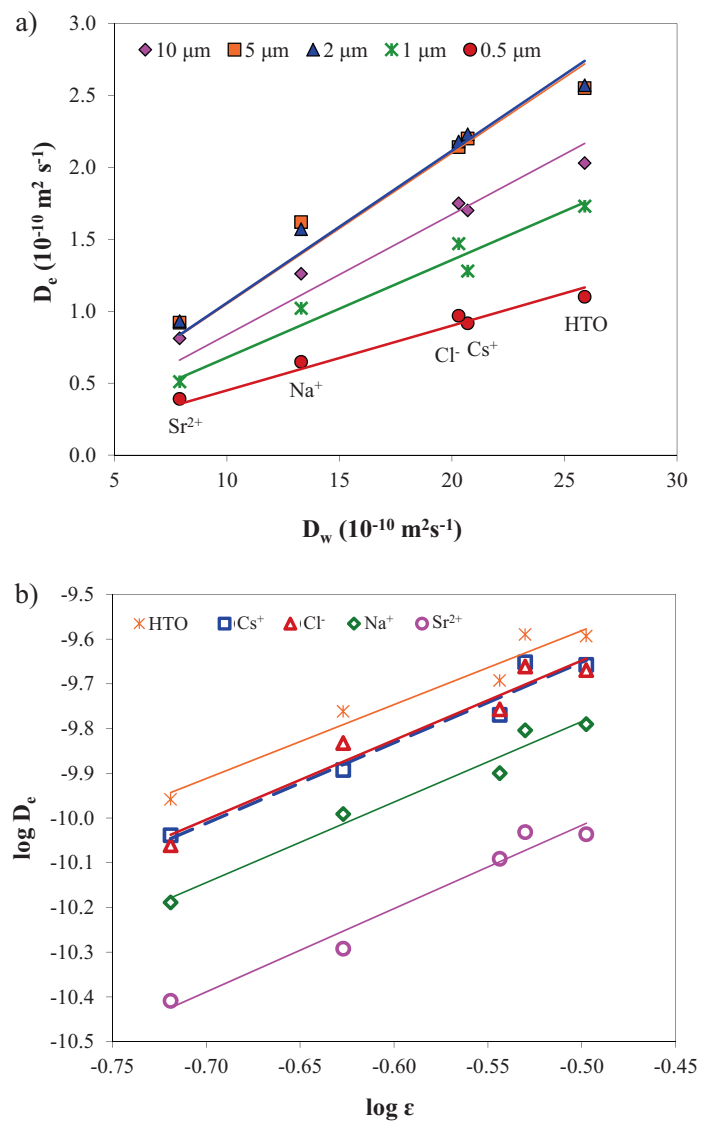

Fig. 3: Archie's correlations in the stainless steel porous filters: (a) $D_{\mathrm{e}}$ as a function of $D_{\mathrm{w}}$ and (b) $\log D_{\mathrm{e}}$ as a function of $\log \varepsilon$. The symbols correspond to the experimental data, and the lines correspond to the fits.

from the slope of the correlation of $D_{\mathrm{e}} v s . D_{\mathrm{w}}$ and the respective porosity (Table 1 ). Higher values of $G$, in this study, imply a poorer interconnection of the pores. The results obtained indicated that the effect of the pore network is the same for all the solutes investigated and that the observed sequence of $D_{\mathrm{e}}$ values must be explained by the intrinsic properties of their diffusion in bulk water. This sequence can be explained well by the Stokes-Einstein equation:

$$
D_{\mathrm{w}}=\frac{k_{B} T}{6 \pi \eta r}
$$

where $k_{\mathrm{B}}$ is Boltzmann's constant, $T$ is the temperature, $\eta$ is the viscosity of the solution, and $r$ is the hydrated radius of the ion. Thus, the largest $D_{\mathrm{e}}$ values were obtained for the neutral HTO. Similar $D_{\mathrm{e}}$ values were obtained for $\mathrm{Cs}^{+}$and $\mathrm{Cl}^{-}$; this result is consistent with the similar hydrated radii of these ions ( $333 \mathrm{pm}$ for $\mathrm{Cl}^{-}$and 328 for $\mathrm{Cs}^{+}$). Lower $D_{\mathrm{e}}$ values were obtained for $\mathrm{Na}^{+}$relative to those of $\mathrm{Cs}^{+}$and $\mathrm{Cl}^{-}$in accordance with the larger hydrated radius
(358 pm) of $\mathrm{Na}^{+}$, and finally, the lowest $D_{\mathrm{e}}$ values were obtained for $\mathrm{Sr}^{2+}$ because it has the largest hydrated radius $(412 \mathrm{pm})[16,17]$.

In addition to the porosity and the size distribution of pores, the topology of the pore space is a crucial property for flow and transport in porous media. The way that pores are interconnected (pore connectivity) may be even more significant than the number and size of the pores. As shown in Table 1, the porosity increased with pore size in the stainless steel filters up to the $5-\mu \mathrm{m}$ filters, but this increase was not observed for the $10-\mu \mathrm{m}$ filters, which had a lower porosity. The opposite trend was observed for the $G$ values. This fact might be related to the production process for these filters, in which a higher pore diameter did not consistently lead to a higher porosity and connectivity. The $D_{\mathrm{e}}$ of a given solute increased with the filter porosity (up to the maximum $D_{\mathrm{e}}$ values for porosities of approximately 0.30-0.32) but not with the pore size. Therefore, the experimental results indicated that the filter pore size is not the critical parameter governing the $D_{\mathrm{e}}$ values. Instead, the dependence between $D_{\mathrm{e}}$ and the porosity values can be examined based on Archie's empirical relationship in its general form $[10,18]$ :

$$
D_{\mathrm{e}}=A \cdot \varepsilon^{m}
$$

where $A$ is a pre-exponential factor, which is expected to equal $D_{\mathrm{w}}$ for an inert porous medium in the limiting case of $\varepsilon \rightarrow 1 ; m$ is the empirical cementation exponent, which with the porosity, is a measure of how the pore space is arranged in terms of pore size and connectivity (pore geometry) [10]. Thus, the cementation exponent characterises the tendency of the pore network to increase the diffusive resistivity. Note the formal analogy between Eq. (2) and Eq. (4) for the identity of $A$ and $D_{\mathrm{w}}$, from which it follows that $G=\varepsilon^{1-m}$. Archie's relation can also be applied to simultaneously derive the $m$ and $A$ values for each solute through the log transformation of Eq. (4),

$$
\log D_{\mathrm{e}}=\log A+m \cdot \log \varepsilon
$$

thus, $\log D_{\mathrm{e}}$ can be correlated to $\log \varepsilon$ for every solute. The $A$ and $m$ values can then be derived from the intercept and slope of the regression curve, respectively. As shown in Figure $3 \mathrm{~b}$, all the correlations were excellent $\left(R^{2}>0.93\right)$, and Table 2 summarises the $A$ and $m$ values calculated for all the solutes. The corresponding $D_{\mathrm{w}}$ values from the literature are also included for comparison.

Reasonably constant values of $m$ were obtained for all the solutes, from 1.7 to 1.9; this result suggests that the pore geometry is quite homogeneous in the stainless steel filters for the various pore sizes and porosities evaluated. 
Table 2: The $m$ factor and $D_{\mathrm{w}}$ values derived from the correlations of $\log D_{\mathrm{e}}$ as a function of $\log \varepsilon$ and the literature $D_{\mathrm{w}}$ values for each solute. The standard errors for $m$ and $D_{\mathrm{w}}$ are given within the parentheses.

\begin{tabular}{lrrr}
\hline Solute & $\begin{array}{r}\text { Derived } \\
\boldsymbol{m} \text { factor }\end{array}$ & $\begin{array}{r}\mathbf{A} \\
\left(\mathbf{1 0} \mathbf{1 0}^{-10} \mathbf{m}^{2} \mathbf{~ s}^{-1}\right)\end{array}$ & $\begin{array}{r}\text { Literature } D_{\mathbf{w}} \\
\left(\mathbf{1 0} \mathbf{1 0}^{-10} \mathbf{m}^{2} \mathbf{s}^{-1}\right)\end{array}$ \\
\hline $\mathrm{HTO}$ & $1.7(0.2)$ & $19(5)$ & $22.3^{\mathrm{a}}-25.9^{\mathrm{b}}$ \\
$\mathrm{Cs}^{+}$ & $1.8(0.2)$ & $18(5)$ & $20.7^{\mathrm{c}}$ \\
$\mathrm{Cl}^{-}$ & $1.8(0.2)$ & $19(6)$ & $20.3^{\mathrm{c}}$ \\
$\mathrm{Na}^{+}$ & $1.8(0.2)$ & $13(3)$ & $13.3^{\mathrm{c}}$ \\
$\mathrm{Sr}^{2+}$ & $1.9(0.2)$ & $8(2)$ & $7.9^{\mathrm{c}}$ \\
\hline
\end{tabular}

${ }^{\mathrm{a}}[14],{ }^{\mathrm{b}}[15],{ }^{\mathrm{c}}[13]$.

Furthermore, the $m$ values obtained in these filters were lower than the values reported in the literature for natural samples and indicated a less complex pore geometry because of a more ordered aggregation of particles. Values of $m$ in the literature ranged from theoretical values of 1.35 , for a homogeneously connected isotropic medium of spherical particles [19], to higher values (up to 3), corresponding to the more complex pore geometries present in natural samples. For example, a value of $m=2.3$ was estimated for limestone and sandstone [19], $m=2.5$ was estimated for Opalinus clay and Boom clay [7] and $m=3$ was estimated for Oxfordian limestones and argillite [20].

The $A$ values for $\mathrm{Cs}^{+}, \mathrm{Cl}^{-}, \mathrm{Na}^{+}$and $\mathrm{Sr}^{2+}$ deduced from the respective correlations were similar to the literature values of $D_{\mathrm{w}}$; thus, these values validated the assumption of bulk water properties for the pore fluid, and suggested that the stainless steel filters behaved as inert porous media and did not interact with the solute. This result is not given for reactive porous media, such as clays, in which $A$ does not equal $D_{\mathrm{w}}$, as in montmorillonite (see, e.g., Glaus et al., 2010). Therefore, in view of the obtained results, unused stainless steel filters are considered to be appropriate for use as confining porous filters in through-diffusion experiments. Additionally, Archie's relationship might also be used to roughly estimate the $D_{\mathrm{w}}$ values of a given solute in stainless steel porous filters.

\subsection{Effective diffusion coefficients for VYCOR ${ }^{\circledR}$ glass, $\mathrm{Al}_{2} \mathrm{O}_{3}$ and PEEK porous filters}

Table 3 shows the measured effective diffusion coefficients of $\mathrm{HTO}, \mathrm{Cs}^{+}, \mathrm{Cl}^{-}$and $\mathrm{SeO}_{4}{ }^{2-}$. In contrast to the experiments with steel filters, the $D_{\mathrm{e}}$ values for VYCOR ${ }^{\circledR}$ glass, $\mathrm{Al}_{2} \mathrm{O}_{3}$ and PEEK porous filters were measured only for the
Table 3: The porosities $(\varepsilon)$, effective diffusion coefficients and geometric factors $(\mathrm{G})$ obtained by through-diffusion experiments with $\mathrm{VYCOR}^{\circledR}$ glass, $\mathrm{Al}_{2} \mathrm{O}_{3}$ and PEEK porous filters.

\begin{tabular}{lcccccc}
\hline Material & \multirow{2}{*}{} & \multicolumn{4}{c}{$\boldsymbol{D}_{\mathbf{e}}\left(\mathbf{1 0}^{-10} \mathbf{~ m}^{2} \mathbf{~ s}^{-1}\right)$} & G \\
\cline { 3 - 6 } & & $\mathrm{HTO}$ & $\mathbf{C s}^{+}$ & $\mathrm{Cl}^{-}$ & $\mathbf{S e O}_{4}{ }^{2-}$ & \\
\hline $\mathrm{VYCOR}^{\circledR}$ glass & 0.20 & 2.5 & 2.5 & 1.8 & 0.72 & 2.2 \\
$\mathrm{Al}_{2} \mathrm{O}_{3}$ & 0.30 & 1.9 & 1.9 & 1.5 & 0.42 & 4.2 \\
$\mathrm{PEEK}$ & 0.36 & 1.4 & 1.0 & 1.0 & 0.20 & 7.1 \\
\hline
\end{tabular}

single porosity given in Table 3. In PEEK filters, the sequence of $D_{\mathrm{e}}$ values was $D_{\mathrm{e}}(\mathrm{HTO})>D_{\mathrm{e}}\left(\mathrm{Cl}^{-}\right) \approx D_{\mathrm{e}}\left(\mathrm{Cs}^{+}\right)$ $>D_{\mathrm{e}}\left(\mathrm{SeO}_{4}{ }^{2-}\right)$, which can be explained roughly by the diffusivity of the solvated ions, as already observed in stainless steel filters. In contrast, the sequence of $D_{\mathrm{e}}$ values obtained in the experiments with the VYCOR ${ }^{\circledR}$ glass and $\mathrm{Al}_{2} \mathrm{O}_{3}$ filters did not follow the same trend because the $D_{\mathrm{e}}$ value for $\mathrm{Cs}^{+}$was slightly higher than that expected from the hydrated radius of $\mathrm{Cs}^{+}$. Gimmi and Kosakowski [21] also observed that some sorbing cations, such as caesium, diffused at larger rates than expected in clay materials; this faster diffusion was attributed to surface diffusion, a process that occurs in parallel to pore diffusion. This interaction process could also be hypothesised to occur with caesium in $\mathrm{Al}_{2} \mathrm{O}_{3}$ and especially VYCOR ${ }^{\circledR}$ glass filters with the smallest pores; however, no evidence of this interaction could be deduced from the mass balance of the caesium concentration in the experiments performed with these two materials. Additionally, note that the pore sizes in these two materials are of completely different orders of magnitude, so completely different preconditions exist for such a process to be relevant.

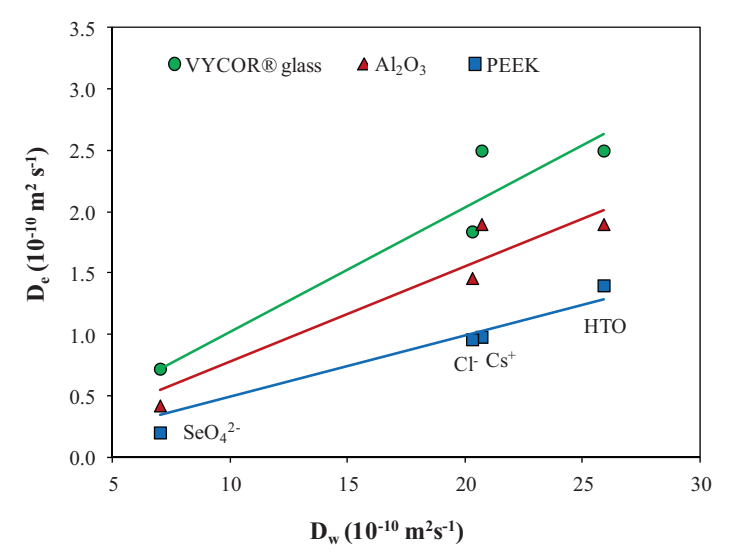

Fig. 4: $D_{\mathrm{e}}$ as a function of $D_{\mathrm{w}}$ for $\mathrm{VYCOR}^{\circledR}$ glass, $\mathrm{Al}_{2} \mathrm{O}_{3}$ and PEEK porous filters. The symbols correspond to the experimental data, and the lines correspond to the fits. 
Another important aspect is that the highest $D_{\mathrm{e}}$ values were obtained for VYCOR ${ }^{\circledR}$ glass, which had the lowest porosity, whereas the lowest values were obtained for PEEK, which had the highest porosity. In contrast, as shown in Table 3, the highest values of $\mathrm{G}$ were obtained for PEEK filters, with the highest porosity, whereas the lowest values were obtained for $\mathrm{VYCOR}^{\circledR}$ glass filters, with the lowest porosity. This result indicates that the $m$ values (see Archie's relation) are not the same for these materials (or according to the equation, $G=\varepsilon^{1-m}$ and suggests that porosity alone is insufficient to explain the differences in solute diffusion in these materials, and the geometry of the pores, including the pore connectivity, might also have an effect.

As shown in Figure 4, despite these irregularities, a fairly linear relation was obtained for the three porous materials between the $D_{\mathrm{e}}$ values of each solute and the respective $D_{\mathrm{w}}$ values obtained from the literature [12-14], except for $\mathrm{SeO}_{4}{ }^{2-}$, for which a $D_{\mathrm{w}}$ value of $7 \times 10^{-10} \mathrm{~m}^{2} \mathrm{~s}^{-1}$, obtained in this work by a capillary method [22], was used. The correlation in the PEEK filters was excellent $\left(R^{2}=\right.$ $0.95)$, but was slightly worse in VYCOR ${ }^{\circledR}$ glass $\left(R^{2}=0.89\right)$ and $\mathrm{Al}_{2} \mathrm{O}_{3}\left(R^{2}=0.91\right)$ filters because of the different pattern of the $D_{\mathrm{e}}$ values obtained for $\mathrm{Cs}^{+}$relative to the remaining solutes. The correlations improved for the two materials $\left(R^{2}=0.97\right.$ for VYCOR ${ }^{\circledR}$ glass and $R^{2}=0.99$ for $\mathrm{Al}_{2} \mathrm{O}_{3}$ ) if the $\mathrm{Cs}^{+}$values were excluded; this improvement indicated that interaction processes possibly affected the diffusion of $\mathrm{Cs}^{+}$in these materials. Nevertheless, these processes must be considered to be merely speculative because of the few number of points considered.

\section{Conclusions}

This work demonstrated that testing the correlation between $D_{\mathrm{e}}$ and $D_{\mathrm{w}}$ values in a series of uncharged, posi- tively and negatively charged solutes in presumably inert porous media is a useful strategy for the evaluation of the suitability of a given material for use as a porous filter in through-diffusion experiments. This strategy allows information to be obtained about the potential interactions of the solutes with the filter and anticipates the possible effects of the pore geometry of the filter material on the $D_{\mathrm{e}}$ values obtained for different solutes, as a preliminary step in the design of diffusion experiments. Thus, filter materials that result in good correlations and that allow a good estimate of the $D_{\mathrm{w}}$ values for a solute from Archie's relationship are suitable for diffusion experiments. However, there are also other criteria for the selection of filter materials, such as the cementation factor in Archie's relationship, when dealing with different porosities of the same material, or the geometrical factor, which permits comparisons among materials. The lower the $D_{\mathrm{e}}$ values obtained for a filter, the less suitable the filter material is. The mechanical stability or the presence of solute-material interaction processes are also other criteria to consider.

Therefore, for high $D_{\mathrm{e}}$ values, stainless steel filters with a pore size of 2 to $5 \mu \mathrm{m}$ or $\mathrm{VYCOR}^{\circledR}$ glass filters would be the most suitable materials. However, VYCOR ${ }^{\circledR}$ glass may have a potential interaction with $\mathrm{Cs}^{+}$whereas stainless steel filters showed a good correlation for a wide range of solutes.

Acknowledgement: This research was funded by the Spanish Government (CICYT, contracts CTM200801147/TECNO and CTM 2011-27211) and the Generalitat de Catalunya (2009SGR1188). The authors would like to thank the Paul Scherrer Institut and Nagra for material support of this research. David Aldaba was awarded a PhD fellowship by the Universitat de Barcelona.

Received August 16, 2013; accepted February 10, 2014.

\section{References}

1. OECD/NEA. The Environmental and Ethical Basis of Geological Disposal of Long-Lived Radioactive Wastes. A Collective Opinion of the Radioactive Waste Management Committee of the OECD Nuclear Energy Agency, OECD, Paris (1995).

2. Andra. Dossier 2001 Argile: Progress report on feasibility studies \& research into deep geological disposal of highlevel, long-lived waste. Synthesis Report, Andra, Paris, France (2001).

3. Nagra. Project Opalinus Clay: Safety Report- Demonstration of disposal feasibility for spent fuel, vitrified high-level waste and long-lived intermediate-level waste (Entsorgungsnachweis). Nagra Technical Report NTB-02-05, Nagra, Wettingen, Switzerland (2002).

4. Enresa. El almacenamiento geológico profundo de los residuos radiactivos de alta actividad: Principios básicos y tecnología. Enresa, Madrid, España (2001).

5. Shackelford, C. D.: Fundamentals of soil behaviour (Book review). J. Contam. Hydrol. 7, 177 (1991).

6. Molera, M., Eriksen, T.: Diffusion of ${ }^{22} \mathrm{Na}^{+},{ }^{85} \mathrm{Sr}^{2+},{ }^{134} \mathrm{Cs}^{+}$ and ${ }^{57} \mathrm{Co}^{2+}$ in bentonite clay compacted to different densi- 
ties: experiments and modelling. Radiochim. Acta. 90, 753 (2002).

7. Van Loon, L. R., Soler, J. M., Jakob, A., Bradbury, M. H.: Effect of confining pressure on the diffusion of $\mathrm{HTO}^{36} \mathrm{Cl}^{-}$and ${ }^{125} \mathrm{I}^{-}$in layered argillaceous rock (Opalinus Clay): diffusion perpendicular to the fabric. Appl. Geochem. 18, 1653 (2003).

8. Glaus, M. A., Frick, S., Rossé, R., Van Loon, L. R.: Comparative study of tracer diffusion of $\mathrm{HTO},{ }^{22} \mathrm{Na}^{+}$and ${ }^{36} \mathrm{Cl}^{-}$in compacted kaolinite, illite and montmorillonite. Geochim. Cosmochim. Acta.74, 1999 (2010).

9. Glaus, M. A., Rossé, R., Van Loon, L. R., Yaroshchuk. A.E.: Tracer diffusion in sintered stainless steel filters: measurement of the effective diffusion coefficients and implications for diffusion studies with compacted clays. Clays and Clay Minerals 56(6), 677 (2008).

10. Boving, T. B., Grathwohl, P.: Tracer diffusion coefficients in sedimentary rocks: Correlation to porosity and hydraulic conductivity. J. Contam. Hydrol.53, 85 (2001).

11. Glaus, M. A., Müller, W., Van Loon, L. R.: Diffusion of iodide and iodate through Opalinus Clay: Monitoring of the redox state using an anion chromatographic technique. Appl. Geochem. 23, 3612 (2008).

12. Li, Y-H., Gregory, S. Diffusion of ions in sea water and in deepsea sediments. Geochim. Cosmochim. Acta 88, 703 (1974).

13. Mills, R.: Self-diffusion in normal and heavy water in the range $1-45^{\circ}$. J. Phys. Chem. 77, 685 (1973).
14. Pruppacher, H. R.: Self-diffusion coefficient of supercooled water. J. Chem. Phys. 56, 101 (1972).

15. Shackelford, C. D., Daniel, D. E.: Diffusion in saturated soil: I: Background. J. Geotech. Eng. ASCE 117, 467 (1991).

16. Conway, B. E.: Ionic hydration in chemistry and biophysics, New York: Elsevier Scientific Pub. Co., 1981.

17. Dove, P. M., Nix, C. J.: The influence of the alkaline earth cations, magnesium, calcium and barium on the dissolution kinetics of quartz. Geochim. Cosmochim. Acta 61, 3329 (1997).

18. Archie, G. E.: The electrical resistivity log as an aid in determining some reservoir characteristics. Trans. AIME 146, 54 (1942).

19. Bruggeman, D. A. G.: Berechnung verschiedener physikalicher Konstanten von heterogenen Substanzen. Ann. Phys. 24, 636 (1935).

20. Descostes, M., Blin, V., Bazer-Bachi, F., Meier, P., Grenut, B., Radwan, J., Schlegel, M. L., Buschaert, S., Coelho, D., Tevissen, E.: Diffusion of anionic species in Callovo-Oxfordian argillites and Oxfordian limestones (Meuse/Haute-Marne, France). Appl. Geochem. 23, 655 (2008).

21. Gimmi, T., Kosakowski, G.: How mobile are sorbed cations in clays and clay rocks? Environ. Sci. Technol. 45, 1443 (2011).

22. Mills, R., Perera, A., Simonin, J. P., Orcil, L., Turq, P.: Coupling of diffusion processes in multicomponent electrolyte solutions. J. Phys. Chem. 89, 2722 (1985). 